\title{
PENYULUHAN HUKUM TENTANG BAHAYA NARKOBA DI SMA NEGERI 4 PASARWAJO KABUPATEN BUTON
}

\author{
Edy Nurcahyo, La Gurusi, Rizki Mustika Suhartono dan Ernawati \\ Fakultas Hukum, Universitas Muhammadiyah Buton, Indonesia \\ E-mail: cahyonur3dy@gmail.com
}

\begin{abstract}
This community service aims to provide knowledge and understanding of the dangers of narcotics for SMA Negeri 4 Pasarawajo. This community service is expected to be able to provide legal awareness to students about the dangers of drugs from a legal and health perspective. The methods used in the implementation of activities are counseling, lectures and discussions. The results and discussion, namely Community Service is legal counseling by involving students to practice providing legal education in front of students of SMA 4 Pasarwajo, Buton Regency. Legal education about the dangers of drugs is needed for the youth generation, considering that adolescents are easily influenced by deviant behavior, including the abuse of illegal drugs.
\end{abstract}

Keywords: Legal counseling, The dangers of drugs

\begin{abstract}
Abstrak
Pengabdian kepada masyarakat ini bertujuan untuk memberikan pengetahuan dan pemahaman tentang bahaya narkotika terhadap siswa SMA Negeri 4 Pasarawajo. Pengabdian kepada masyarakat ini diharapkan mampu memberikan kesadaran hukum terhadap siswa akan bahaya narkoba dari prespektif hukum dan kesehatan. Metode yang digunakan dalam pelaksanaan kegiatan adalah penyuluhan, ceramah dan diskusi. Hasil dan pembahasan yaitu Pengabdian Kepada masyarakat ini adalah penyuluhan hukum dengan melibatkan mahasiswa untuk praktek memberikan penyuluhan hukum di hadapan siswa-siswa SMA 4 Pasarwajo Kabupaten Buton. Penyuluhan hukum tentang bahaya narkoba sangat dibutuhkan bagi generasi remaja, mengingat usia remaja mudah sekali terpengaruh pada perilaku menyimpang, termasuk dalam penyalahgunaan obat-obatan terlarang.
\end{abstract}

Kata Kunci : Penyuluhan Hukum, Bahaya Narkoba

\section{PENDAHULUAN}

Permasalahan narkoba di Indonesia masih sangat urgen dan kompleks. Hal itu terbukti dengan semakin bertambahnya jumlah penyalahguna dan pecandu narkoba secara signifikan. Dampak penyalahgunaan narkoba tidak hanya mengancam kelangsungan hidup dan masa depan penyalahgunanya saja, namun juga mengancam mesa depan bangsa dan negara (Jimmy Simangunson, 2015). Dari data-data dan hasil penelitian Badan Narkotika Nasional (BNN), bahwa penyalahgunaan dan peredaran gelap narkotika terbukti merasuk nyaris ke pelosok-pelosok kota dan desa serta ke lapisan masyarakat. Data BNN menunjukkan kasus-kasus Tindak Pidana Narkotika dari tahun ke tahun selalu meningkat, pada Tahun 2001 hanya tercatat 3.617 kasus. Beberapa tahun berikutnya angka tersebut tidak mengalami penurunan, pada Tahun 2008 data meningkat lebih dari delapan kali lipat menjadi 29.359 kasus. Hingga juni 2009, tercatat Tindak Pidana Narkotika telah mencapai 33.958 kasus. Hasil penelitian BNN Tahun 2008, menunjukkan 1,99 persen penduduk Indonesia telah menyalahgunakan Narkotika (Jurnal BNN, 2009).

Penyalahgunaan narkoba di Indonesia sudah sampai pada tingkat yang sangat mengkhawatirkan, fakta di lapangan menunjukkan 50\% penghuni lapas (Lembaga 
Pemasyarakatan) disebabkan oleh kasus narkoba. Berita criminal di media massa, baik di media cetak mapupun media elektronik dipenuhi oleh berita tentang penyalahgunaan narkoba (Fransiska Novita Eleanora, 2011). Bahkan, penyalahgunaan narkoba telah menimbulkan banyak korban dan menimbulkan permasalahan sosial (Ahmad Syafi'i, 2009).

Penyebarluasan terhadap peredaran dan penyalahgunaan narkotika semakin meluas dan hampir tidak bisa dicegah. Mengingan hampir setidap orang dapat dengan mudah memperoleh narkotika dari oknum-oknum yang tidak bertanggung jawab. Hal tersebut sering terdengar dari wacana yang sering beredar di masyarakat bahwa Bandar narkotika saat ini tidak hanya senang mencari mangsa di daerah diskotik, tempat pelacuran, dan tempat-tempat perkumpulan seperti genk remaja, bahkan telah merambat ke lingkungan sekolah dan kampus. Tentu hal ini membuat para orang tua, masyarakat dan pemerintah, pimpinan sekolah dan perguruan tinggi khawatir akan penyearan narkotika yang sangat meraja lela (Sri Rahayu dkk, 2014).

Kondisi psikologis remaja sangat labil, sehingga mudah terpengaruh pada perbuatan negatif yang dilakukan oleh teman atau terpengaruh lingkungan yang tidak baik. Banyak remaja yang menjadi pecandu narkoba awanya hanya sekedar coba-coba mengkonsumsi narkoba yang ditawarkan oleh temannya. Namun lambat laun narkoba menjadi petaka bagi dirinya (Suwari Akhmaddhian, 2019). Berdasarkan uraian dan problemtik tersebut, perlu menyelenggarakan penyuluhan hukum terhadap remaja sebagai upaya prefentif untuk mencegah terjadinya penyalagunaan narkoba di kalangan remaja, oleh karna itu dalam penyuluhan hukum ini mengambil judul "Penyuluhan Hukum tentang Bahaya Narkoba di SMA Negeri 4 Pasarwajo Kabupaten Buton".

\section{METODE PELAKSANAAN}

Dalam pengabdian kepada masyarakat menggunakan metode penyuluhan hukum, yaitu menyuluh atau memberikan penjelasan tentang bahaya dan ancaman hukum bagi pelaku penyalahgunaan narkoba. Dalam penyuluhan hukum ini melibatkan sejumlah mahasiswa Fakultas Hukum Universitas Muhammadiyah Buton bertempat di SMA Negeri 4 Pasarwajo Kabupaten Buton.

\section{HASIL DAN PEMBAHASAN}

\section{Pemahaman tentang Narkoba}

Narkoba adalah zat atau bahan yang berbahaya yang mempengaruhi kondisi kejiwaan atau psikologi seseorang, baik itu pikiran, prilaku ataupun perasaan seseorang dimana efek samping dari penggunaan obat ini adalah kecanduan atau menyebabkan ketergantungan terhadap zat atau bahan ini. Ada beberapa golongan yang termasuk narkoba yaitu: (1) Narkotika; (2) Psikotropika; dan (3) Zat Adiktif.

\section{a) Narkotika}

Di Indonesia, narkotika diatur dalam Undang-Undang Nomor 35 Tahun 2009 Tentang Narkotika. Dalam Undang-Undang Narkotika, Narkotika adalah zat atau obat yang berasal dari tanaman atau bukan tanaman, baik sintesis maupun semisintesis, yang dapat menyebabkan penurunan dan perubahan kesadaran, hilangnya rasa, mengurangi 
sampai menghilangkan rasa nyeri, dan dapat menimbulkan ketergantungan, yang dibedakan ke dalam golongan-golongan.

Dalam UU narkotika, golongan narkotika tersebut dibagi menjadi tiga, yaitu: (1) Golongan I merupakan narkotika dapat digunakan untuk kepentingan ilmu pengetahuan dan teknologi dan reagensia diagnostik. (2) Golongan II merupakan narkotika yang dipergunakan sebagai obat, penggunaan sebagai terapi, atau dengan tujuan pengembangan ilmu pengetahuan, serta memiliki potensi ketergantungan sangat tinggi, contohnya: Morfin, Petidin. Golongan III merupakan narkotika yang digunakan sebagai obat dan penggunaannya banyak digunakan untuk terapi, serta dipergunakan untuk pengembangan ilmu pengetahuan dan memiliki potensi ketergantungan ringan, contohnya: Kodein. Narkotika Golongan I dilarang diproduksi kecuali untuk pengembagan ilmu pengetahuan dan teknologi, dilarang digunakan untuk kepentingan pelayanan kesehatan, dilarang untuk dipergunaakan terapi, karena memiliki potensi ketergantungan sangat tinggi, seperti ganja, Cocain, Sabusabu, Opium, dan Heroin. Pengguna narkotika dapat dibagi menjadi dua yaitu; (1) Pecandu Narkotika (Pasal 1 angka 13 jo Pasal 54 jo Pasal 127); (2) Penyalahguna narkotika (Pasal 1 angka 15 jo Pasal 54 jo Pasal 127).

\section{b) Psikotropika}

Psikotropika adalah zat atau obat, baik alamian maupun sintesis bukan narkotika, yang berkhasiat psikoaktif melalui pengaruh selektif pada susunan saraf pusat yang menyebabkan perubahan perilaku atau perubahan khas pada aktifitas mental dan dibagi menjadi beberapa golongan.

Dalam Undang-Undang Nomor 5 Tahun 1997 Tentang Psikotropika, Psikotropika terbagi menjadi 4 Golongan. Golongan psikotropika tersebut yaitu: (1) Golongan I yaitu obat psikotropika dengan daya candu yang sangat kuat, seperti Ekstasi, LAD, STP. (2) Golongan II yaitu psikotropika dengan daya candu kuat, contohnya retalin, metilfenidat, dan amfetamin yang berguna untuk penelitian dan pengobatan. (3) Golongan III yaitu psikotropika dengan daya candu sedang dan berguna bagi penelitian dan pengobatan, misalnya flunitrazepam, pentobarbital, buprenorsina, lumibal, dan sebagainya. (4) Golongan IV yaitu psikotropika dengan daya candu ringan dan boleh digunakan untuk pengobatan medis, contohnya diszepam, nitrazepam, dan lain-lain.

\section{c) Zat Adiktif}

Zat adiktif adalah haban atau zat yang berpengaruh psikoaktif diluar narkotika dan psikotropika, meliputi: (1) Minuman Beralkohol; (2) Inhalasi; (3) Tembakau.

\section{Efek Narkoba}

Berdasarkan efeknya terhadap perilaku yang ditimbulkan dari pengguna narkoba dapat dibagi menjadi beberapa golongan, yaitu: (1) Golongan Depresan; (2) Golongan Stimulan; (3) Golongan Halusinogen.

\section{Bahaya Narkoba}

Penggunaan narkoba dapat menyebabkan efek sangat buruk, banyak pengguna narkoba memiliki gangguan mental dan penyimpangan perilaku. Hal itu karena susunan 
saraf pusat di otak telah terganggu, sehingga menyebabkan terganggunya fungsi kognitif 9alam pikiran), afektif (alam perasaan, emosi), psikomotorik (perilaku) dan aspek sosial. Berikut adalah bahaya narkoba terhadap fisik, psikologi dan lingkungan sosial:

a) Bahaya Narkoba Terhadap Fisik

Mengkonsumsi norkoba berbahaya terhadap fisik, diantaranya yaitu: 1) Gangguan pada sistem syaraf (neurologis); 2) Gangguan pada jantung dan pembuluh darah (kardiovaskuler); 3) Gangguan pada kulit (dermatologis); 4) Gangguan pada paruparu (pulmoner); 5) Imsomnia; 6) Gangguan terhadap kesehatan reproduksi dan gangguan fungsi seksual; 7) Berisiko tertular penyakit HIV disebabkan penggunaan jarum suntik yang bergantian; 8) Berisiko kematian ketika over dosis; 9) Mendapatkan Hukuman Pidana.

b) Bahaya narkoba Terhadap Psikologi

Mengkonsumsi narkoba juga berbahaya tehadap aspke psikologi, diantaranya yaitu: 1) Kehilangan rasa percaya diri; 2) Gelisah dan gundah gulana; 3) Susah berkonsentrasi; 4) Tingkah laku berutal; 5) Perasaan cemas.

c) Bahaya Narkoba Terhadap Lingkungan Sosial

Penggunaan narkoba juga berdampak terhadap lingkungan sosial, diantaranya adalah: 1) Anti sosial dan asusila; 2) Mengalami gangguan mental; 3) Menyusahkan dan menjadi beban keluarga; 4) Masa depan suram; 5) Kehilangan kehormatan dan harga diri

\section{Upaya Pencegahan}

Narkoba sangat mengkawatirkan dan membahayakan, penggunaannya yang luas di masyarakat menimbulkan banyak kerugian, karena narkoba menghancurkan potensi sumber daya manusia, siapapun yang menjadi pecandu narkoba sudah dapat dipastikan kualitas sumber dayanya menjadi lemah dan tak berdaya guna. Sehingga perlu dilakukan pencegahan bagi semua kalangan. Adapun upaya pencegahan yang dilakukan yaitu: (1) Jangan pernah menggunakan narkoba; (2) mengetahui dampak negaif dan bahaya narkoba; (3) Memiliki pergaulan yang baik; (4) Mengikuti kegiatan yang positif; (5) Memperdalam Agama; (3) mengetahu sanksi pidana akibat penyalahgunaan narkoba

\section{Sanksi Pidana Penyalahgunaan Narkoba}

a) Sanksi Penyalahgunaan Narkotika yaitu Undang-Undang RI Nomor 35 Tahun 2009, sanksi bagi pelaku penyalahgunaan narkoba tergolong sanksi pidananya sangat berat, sanksi pidana dalam UU tersebut diatur mulai Pasal 111 s/d Pasal 148. Sanksi penjara pada Pasal 111, 112, 113, dan 114 minimal 4 tahun penjara dan maksimal hukuman mati.

b) Sanksi Penyalahgunaan Psikotropika yaitu Undang-Undang RI Nomor 5 Tahun 1997, ketentuan tentang Pasal Tindak Pidana penyalahgunaan narkoba diatur mulai Pasal 59 s/d Pasal 72. Dalam Pasal 59 ancaman pidana minimal 4 tahun dan maksimal hukuman mati atau penjara seumur hidup.

\section{Rehabilitasi}

Pecandu Narkotika dan korban penyalahgunaan Narkotika wajib menjalani rehabilitasi medis dan rehabilitasi sosial. Rehabilitasi merupakan proses pengobatan atau 
pemulihan agar pecandu dapat terbebas dari ketergantungan narkotika dan dapat melaksanakan fungsi sosial di tengah kehidupan masyarakat. Ada dua jenis rehabilitasi, yaitu rehabilitasi medis dan rehabilitasi sosial. Rehabilitasi medis adalah suatu proses kegiatan pengobatan secara terpadu sosial adalah suatu proses kegiatan pemulihan secara terpadu, baik fisik, mental maupun sosial, agar bekas pecandu narkotika dapat melaksanakan fungsi sosial dalam kehidupan masyarakat.
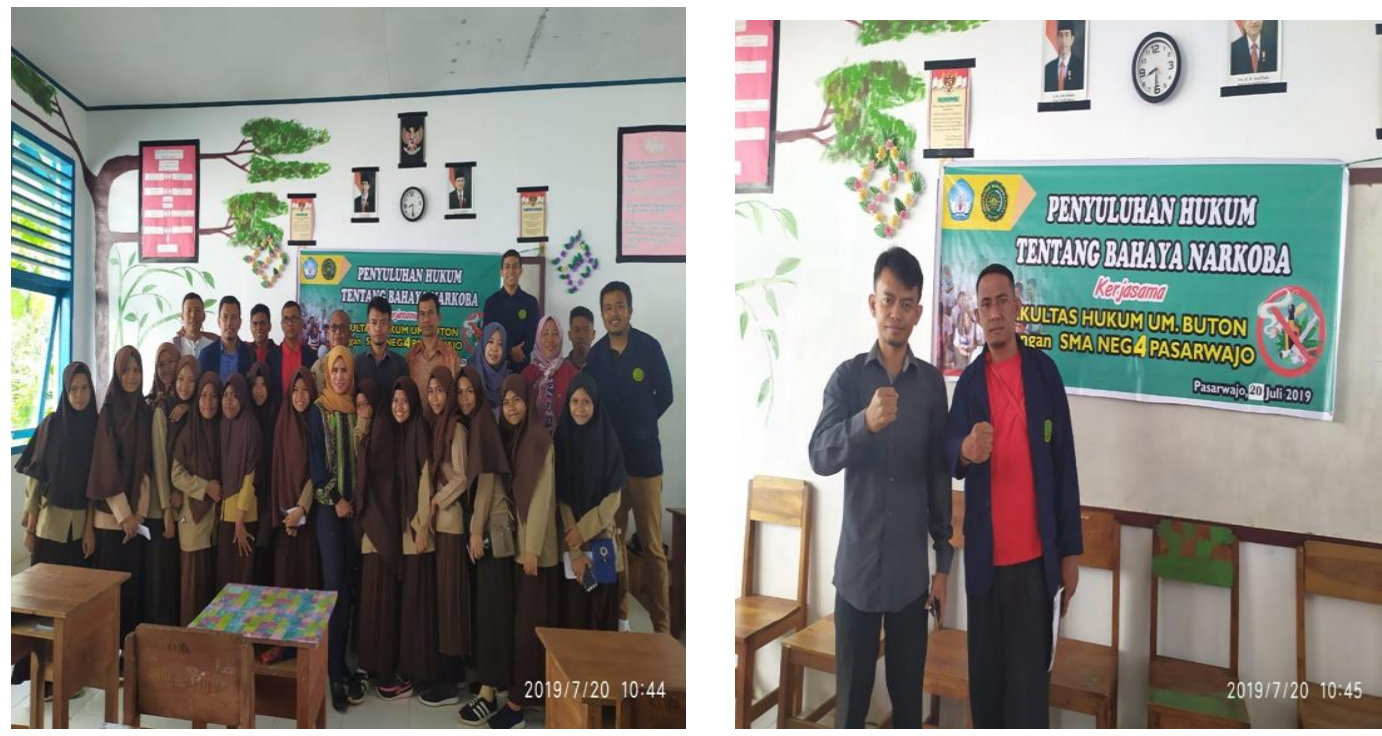

Gambar. Penyuluhan Hukum Tentang Bahaya Narkoba

\section{SIMPULAN}

Berdasarkan hasil pelaksanaan kegiatan dalam kegiatan penyuluhan hukum tersebut diatas dapat disimpulkan sebagai berikut: 1) Peserta penyuluhan baik dosen maupun mahasiswa fakultas hukum Universitas Muhammadiyah Buton memiliki kemampuan dalam menjelaskan dan menguraikan isi Undang-Undang narkotika kepada Siswa-Siswi SMA 4 Pasarwajo dengan penyampaian materi yang mudah dipahami; 2) Siswa-Siswi SMA 4 Pasarwajo sebagai peserta yang menerima penyuluhan memiliki antusias yang tinggi dalam mengikuti menyuluhan hukum tentang bahaya narkoba. Materi yang disampaikan dapat difahami dengan baik, hal tersebut ditunjukkan dengan pertanyaan dan diskusi di ruang kelas tentan bahaya narkoba.

\section{SARAN}

Untuk mencegah terjadinya penyalahgunaan Norkoba oleh kalangan pelajar dibutuhkan penyuluhan-penyuluhan hukum tentang bahaya narkoba. Semua pihak harus turut serta menjaga generasi calon penerus bangsa agar terhidar dari perbuatan penyalahgunaan narkoba.

\section{UCAPAN TERIMA KASIH}

Penulis mengucapkan terimakasih kepada Rektor Universitas Muhammadiyah Buton, Ketua LPPM, dan Dekan Fakultas Hukum yang telah mendukung terselenggaranya pengabdian masyarakat berupa kegitan penyuluhan hukum, sehingga kegiatan pengabdian masyarakt dapat terselenggara dengan baik. 


\section{DAFTAR PUSTAKA}

Ahmad Syafi'i. (2009). Penyalahgunaan Narkoba dalam Prespektif Hukum Positif dan Hukum Islam. Hunafia: Jurnal Studia Islamika. Vol. 6 No. 1.2009.

Andisa Shabrian. (2017). Lima Jenis Obat Untuk Depresi dan Insomnia yang Ternayat masuk Golongan Psikotropika. Available at https://hellosehat.com/hidupsehat/fakta-unik/golongan-obat-psikotropika/

Bahaya Narkoba, Available at https://www.admedika.co.id/index.php/id/medias/sehatiblog/item/75-bahaya-narkoba

Eric Manurung. (2018). Jenis Golongan dan Penerapan Pasal yang Dikenakan UU Narkotika. Available at https://www.hukumonline.com/berita/baca/lt5a799bc2a041a/jenis-golongandan-penerapan-pasal-yang-dikenakan-pada-uu-narkotika-oleh--eric-manurung/

Fransiska Novita Eleanora (2011). Bahaya Penyalahgunaan Narkoba Serta Usaha Pencegahan dan Penanggulangan (Suatu Tinjauan Teoritis). Jurnal Hukum Fakultass Hukum Unissula. Vol 25. No. 1. 2011.

Jimmy Simangunson. (2015). Penyalahgunaan Narkoba di kalangan Remaja (Studi Kasus pada Badan Narkotika Nasional Kota Tanjungpinang). Available at http://jurnal.umrah.ac.id/wp-content/uploads/gravity_forms/1ec61c9cb232a03a96d0947c6478e525e/2015/09/E-jurnal-jimmy.pdf

Sri Rahayu, Bambang Subiantoro, Yulia Monita, Dheni Wahyudi. (2014). Penyuluhan Pencegarahan Penyalahgunaan Narkotika di Kalangan Mahasiswa. Jurnal Pengabdian pada masyarakat Universitas Jambi. Vol 29 No. 4.2014.

Sri Rahayu Narkoba/NAPZA. Available at https://rs.unud.ac.id/?p=316

Suwari Akhmaddhian, Penyuluhan Hukum Tentang Prosedur Penanganan Perkara Pidana Di Desa Sangiang, Majalengka. Empowerment : Jurnal Pengabdian Masyarakat,Vol.02 Nomor 02.2019.101-108.

\section{Peraturan Perundang-undangan}

Undang-Undang Republik Indonesia Nomor 5 tahun 1997 Tentang Psikotropika Undang-Undang Republik Indonesia Nomor 35 tahun 2009 Tentang Narkotika Undang-Undang Republik Indonesia Nomor 36 Tahun 2009 Tentang Kesehatan 